\title{
Evaluation of the Healthy Business Award (HBA): improving the accessibility of healthy foods in Wigan borough
}

\author{
N. Dag ${ }^{1}$, J. Grime ${ }^{2}$, L. Lang ${ }^{1}$ and C. Orfila ${ }^{1}$ \\ ${ }^{1}$ School of Food Science and Nutrition, University of Leeds, Leeds, LS2 9JT, UK and ${ }^{2}$ Healthy Business Award Team, \\ Wigan Council, Wigan WN3 $4 H E$, UK
}

Recent reports indicate that one in six meals are purchased and eaten outside the home, equating to an average of $27 \%$ of consumer food expenditure $^{(1)}$ and $11 \%$ of consumer energy intake ${ }^{(2)}$. The Food Standards Agency (FSA) has indicated an urgent need to improve the nutritional quality of foods sold at retail ${ }^{(3)}$. The Healthy Business Award (HBA) is a Wigan-based initiative, commissioned by NHS (Ashton, Leigh and Wigan) which aims to improve the nutritional content of the food available in the borough. The HBA team works with businesses across the food supply chain, providing practical recommendations that enable businesses to improve the nutritional profiles of foods without compromising economic sustainability. The focus is on reducing energy density, and reducing the content of fat, saturated fat, sugar and salt. Recommendations are based on a sound knowledge of food science and nutrition to include the use of healthier ingredients, modification to cooking methods and adjustment of portion sizes. The award is given to businesses which can show that at least $25 \%$ of food items available are classed as 'healthy' according to the FSA's Traffic Light Labelling Guidelines ${ }^{(4)}$. In order to evaluate the effectiveness of the HBA in improving the accessibility of healthy foods, the energy and nutrient content of menu items were analysed before and after the HBA intervention in a number of selected businesses that included small sandwich shops, pubs, staff canteens, nurseries and elderly care homes. In addition, consumer purchase data was recorded for three days (on a Monday, Tuesday and Wednesday) before and after the intervention in order to assess energy and nutrient intake by customers (see table for typical results, below for a small family owned sandwich shop in the city centre of Wigan).

\begin{tabular}{|c|c|c|c|c|c|c|c|c|c|c|}
\hline & \multicolumn{2}{|c|}{ Energy $(\mathrm{kJ} *)$} & \multicolumn{2}{|c|}{ Fat $(\mathrm{g})$} & \multicolumn{2}{|c|}{ Saturated fat $(\mathrm{g})$} & \multicolumn{2}{|c|}{ Sugar $(\mathrm{g})$} & \multicolumn{2}{|c|}{ Salt (g) } \\
\hline & Pre HBA & $\overline{\text { Post HBA }}$ & Pre HBA & Post HBA & Pre HBA & $\overline{\text { Post HBA }}$ & Pre HBA & Post HBA & Pre HBA & Post HBA \\
\hline Average consumer intake $(n>270)$ & 3014.99 & 2007.483 & 22.5 & 19.9 & 8.3 & 7.1 & 12.9 & 8.4 & 2.9 & 2.4 \\
\hline Standard deviation & 1399.13 & 863.322 & 14.4 & 13.7 & 8.9 & 7.3 & 11.8 & 10.4 & 1.7 & 1.2 \\
\hline Percentage change after HBA & \multicolumn{2}{|c|}{$-33 \%$} & \multicolumn{2}{|c|}{$-12 \%$} & \multicolumn{2}{|c|}{$-14 \%$} & \multicolumn{2}{|c|}{$-35 \%$} & \multicolumn{2}{|c|}{$-17 \%$} \\
\hline
\end{tabular}

$* 1 \mathrm{kcal}=4.184 \mathrm{~kJ}$

For this business, the intervention was primarily focused on the replacement of full-fat options with low-fat alternatives (e.g. mayonnaise, spread, milk, etc.), the use of vegetables as bulking ingredients, the removal of salt and butter from some recipes, and the reduction in portion size for popular options (e.g. jacket potatoes). The revised menu was similar to the original with no impact on consumers' choice or cost. The results show that customers were closer to the nutritional guidelines for a single meal (one-third GDA). The Department of Health has estimated the benefits of adhering to the nutritional guidelines to $£ 20$ billion per year ${ }^{(2)}$. Simple changes to catering practice can alter the nutrient and energy intakes of customers, with potential benefits to consumers' long term health.

1. DEFRA (2010) About Family Food, available at: www.defra.gov.uk

2. CABINET OFFICE (2008) Food Matters. Towards a strategy for the 21 st Century, London.

3. FSA (2010) Healthy Catering Committments, available at: www.food.gov.uk

4. FSA (2007) Front-of-pack traffic light signpost labelling, Technical Guidance (2) available at: www.food.gov.uk 